\title{
Examination of Psychological Resilience Levels of High School Students
}

\author{
Berkan Bozdağ $\breve{1}^{1}$ \\ ${ }^{1}$ School of Physical Education and Sports, University of Yozgat Bozok, Yozgat, Turkey \\ *Correspondence: School of Physical Education and Sports, University of Yozgat Bozok, Yozgat, Turkey. Tel: \\ 90-533-059-1040. E-mail: brknbozdag@gmail.com
}

Received: May 11, 2020

Accepted: June 10, $2020 \quad$ Online Published: June 16, 2020

doi:10.5430/wje.v10n3p65

URL: https://doi.org/10.5430/wje.v10n3p65

\begin{abstract}
The general purpose of this research is to examine the psychological resilience of high school students and to compare them with various variances. The population of the research consists of high school students studying in state high schools in Yozgat in the 2019-2020 academic year, and the sampling is consisted of 200 high school students which is determined by the sampling method. In this research, descriptive sequential pattern, which is one of the mixed method research patterns in which qualitative and quantitative research approaches are used together, was applied. Quantitative data were acquired with psychological resilience scale developed by Iş1k (2016). The psychological resilience scale consists of three sub-dimensions: Commitment, control and challenge. Qualitative data were collected using a semi-structured questionnaire and interview technique. Quantitative data were analyzed using the SPSS 22 package program. Since the research data showed normal distribution as a result of the analysis made with the ShapiroWilk test, binary comparisons were analyzed in independent samples with the t-test and ANOVA test. Relational analyzes were realized by using pearson correlation test. In the analysis of qualitative data, content analysis technique was used. According to the research findings gained; there was a statistically significant difference determined in favor of male participants in the sub-dimension of the athlete according to the gender variable of the participants, in favor of the students who exercise in the sub-dimension of control and the sub-dimension according to their sports. According to the academic success level variable, it was concluded that there was no statistically significant difference in the level of commitment and control sub-dimensions and general psychological resilience. In addition, it was determined that there was no statistically significant relationship between the ages of the participants, their sub-dimensions of control, challenge and general psychological resilience. As a result of the content analysis conducted in the qualitative part of the research, it was stated that the effects of the sport in the point of coping with the negative situations where the factors affecting the psychological resilience levels of the students negatively and positively are similar. Consequently, it has been determined that individuals whose sports psychological resilience is negatively affected are one of the methods they frequently use to get rid of the negative situation.
\end{abstract}

Keywords: sports, high school student, resilience

\section{Introduction}

The most important feature that distinguishes humans from other living things is that they can evaluate different perspectives of their problems. In the flow of life, human encounters many problems; While problems can sometimes be constructive, they can also provide an opportunity for development (Maslow, 2001). Especially in the world changing with technology, individuals have started to talk more about psychological problems that affect them directly or indirectly, and these problems have made their life harder. Problems such as loneliness, depression, stress, social phobia, burnout, alienation, egocentrism are some of these. The person who wears down in an effort to struggle against such problems starts to decline in terms of health. World Health Organization defines health not only the absence of a disease or disability, but also the state of being completely physical, mental and socially well (Callahan, 1973).

Accordingly, the person's life balance depends not only on the problem, but also on his ability to cope with it. A problem-free life cannot go beyond an imaginary expectation. Adler (1999) mentioned that the problems are natural by saying that individuals have many problems and cannot be removed from the obligation to solve them. At this 
point, although it is naturally considered that the individual encounters difficulties in his life, it cannot be expected that all individuals can cope with the negative factors in the same degree and time.

In Faller's (2001) survey on psychological articles, happiness, etc. he stated that while he reached 851 records on positive words, he reached 70856 negative keywords on burnout and depression. In this context, studies on the strengths of the individual are very few. Consequently, positive psychology has gained importance as one of the working areas of psychology in order to realize that the change and development of individuals should be satisfied and healthy, not because of their independence, but rather because they are effective in their own lives and to apply this to their lives (Ülker \& Recepoğlu, 2013).

In the field of positive psychology, it is observed that researches are concentrated on topics such as hope, happiness, optimism, forgiveness, well-being, subjective well-being (Gable \& Haidth, 2005). One of the important issues of positive psychology is the concept of psychological resilience. In recent years, the concept of psychological resilience in the field of behavioral sciences has attracted intense attention as a personality trait that reduces stress and supports the ability to cope with events (Judkins \& Rind, 2005; Klag \& Bradley, 2004).

Psychological resilience is defined as the ability of the individual to recover, adapt, or overcome change or disaster effectively in the face of difficult life experiences (Masten and O'Connor, 1989). In this frame, Garmezy (1993) defines psychological resilience as the ability and ability to return to the already existing skills and behaviors that are hidden before the stressful event that the individual experiences. In other terms; Tusaie and Dyer (2004) define psychological resilience as a person's adaptation process against important stress sources such as a trauma, a threat, a tragedy or familial and relational problems, serious health problems, workplace and monetary problems.

Stress can occur due to many things. Today, people are stuck in concrete cities and have a stressful lifestyle. Causes such as future anxiety, unemployment and loneliness cause an increase in stress. (Hayes, 2011). People working in developing technology have reduced their physical work characteristics and have turned towards a more stable lifestyle (Zorba, Cerit, Gümüşdağ, \& Evli, 2013). While some people have a strong and durable psychology that can overcome stress, some people may not be able to overcome their problems (Tugade, Fredrickson, \& Barret, 2004). When the literature is analyzed, the main elements related to the characteristics of resilient persons are; re-creation, experiencing positive emotions, reliable social support and optimism and participation in sports activities (Hefferson \& Boniwell, 2014).

In this preference process, where many individual and environmental differences play a role, it is known that some people get support from humor in the face of negative events, some of them enjoy hobbies such as art, music, books, some are left alone and some of them cope with their friends. For some people, this tool is dealing with a sports branch. (Yağbasanlar, 2018).

One of the keys to feeling psychologically good in this frame is sports. Inal (2014) stated that while listing the psychological benefits of sports, it improves the personality positively and increases the power of struggle and resilience. Yıldırım and Bayrak (2017) stated that there is an improvement in the emotional characteristics of individuals such as self-confidence, personality development, correct expression of emotions and thoughts, awareness of skills and self-control through physical activity and movement. Cihan and Ilgar (2018) stated that sports activities are very important in terms of increasing the life skills of young people. Steptoe and Butler (1996) stated that there is a positive relationship between emotional well-being and participation in sports in adolescents' research on sports participation and emotional well-being. However, Dehkordi (2011) compared the mental health of women who did not exercise with women athletes and stated that athletes were superior to those who did not do sports. A mentally and socially strong individual is thought to be easier to deal with diseases of the age, such as loneliness and stress.

In addition, people who are sports at the center of their life, like every individual, fight stress, which is the disease of the age. Especially athletes are more successful in dealing with stress psychologically. In the face of anxiety and stress, athletes, like everyone, take four major attitudes. These attitudes are learning and challenging to quit and withdraw, to become aggressive, to drown and to deal with (Biçer, 2002). It is possible for athletes who learn to fight the various stressors they encounter in competition conditions and sports lives, thus, they are more durable than individuals who do not do sports psychologically.

Psychological resilience; It consists of three interrelated dimensions: attachment, control and challenge (Holt, Fine, \& Tollefson, 1987; Maddi et al., 2006). Psychological resilience is often explained by the results and the causes of these results. These variables are categorized under three main headings in the literature: Risk factors, protective factors and positive results (Rutter, 2006; Coleman \& Hagell, 2007). Risk factors: The presence of a risk factor is 
needed to explain the presence of psychological resilience (Gizir, 2004). The reaction of individuals to this risk factor is related to their psychological resilience. Protective factors: Protective factors are dynamic mechanisms that help the individual to resist trauma in internal (characteristic) or external (contextual) conditions. Positive adaptation: Positive adaptation is associated with the concepts of coping and competence. It means that the person can cope with the risk factors by using the support of the protective factors and adapt positively to the new situation (Gizir, 2016).

Nowadays, with the pressure of the process to be a good athlete, it is not easy to overcome the stress brought on by the pressure created to maintain good performance. People who can be successful and flexible in adapting to all these negativities are psychologically resilient people. New findings are added to the findings about the rehabilitative effect of the sport in the life of the individual. When the literature is examined, it is noteworthy that the number of psychological resilience is low.

In this context, the level of psychological resilience of high school students, adults of our future, is a matter of curiosity. It is thought that the mental resilience levels of the students who continue their education will be determined by eliminating their negative situations and enabling them to grow psychologically resilient and healthy generations. In addition, it is observed that the findings, conclusions and suggestions obtained from the research can guide researchers and educators who will work on similar topics, including sports psychology experts.

\section{Method}

Explanatory sequential pattern, which is one of the mixed method research patterns in which qualitative and quantitative research approaches are used together, was applied in this research. Mixed method research is a type of research in which a researcher or research team combines elements of quantitative and qualitative research approaches (for example, use of qualitative and quantitative perspectives, data collection, analysis, inference techniques) for the main purposes of the breadth and depth of understanding and verification. (Johnson, Onwuegbuzie and Turner 2007). According to Creswell and PlanoClark (2014), the opinions of the participants cannot be announced directly in quantitative research. Moreover, quantitative researchers remain in the background, their personal bias and interpretation are rarely discussed. Qualitative research compensates for these weaknesses. Thus, the strengths of one approach compensate for the weaknesses of the other approach.

\subsection{Study Group}

In this part, information about the qualitative and quantitative study group of the research is given.

\subsubsection{Quantitative Study Group}

The study group of the research consists of a total of 200 high school students, of which 112 are female and 88 are male, studying in Yozgat in the academic year 2019-2020. The study group was selected by random sampling.

In Table 1, frequency and percentage distributions regarding students' demographic characteristics are presented.

When Table 1 is examined, it is seen that the frequency and percentage distribution is given according to the demographic characteristics of the students. Considering the distribution of students by gender, $112(56.0 \%)$ female students and $88(54.0 \%)$ male students participated in the study. When the distribution of students according to their sports status is examined, there are 76 students that do sports (38.0\%) students, and 124 sedentary students that do not do sports $(62.0 \%)$. When the distribution of students according to their ages is examined, $34(17.0 \%)$ students aged 14 and below, $92(46.0 \%)$ students aged 15, $57(8.0 \%)$ students aged 16, There is $1(5 \%)$ student who is over 19. When the distribution of students according to their branches is analyzed, there are $18(23.7 \%)$ students that do individual sports and $58(76.3 \%)$ students that are in team sports. When the distribution of students according to their academic success levels is analyzed, there are $33(16.5 \%)$ students with good academic success levels, $132(66.0 \%)$ students with a medium level and $35(17.55 \%)$ students with a bad level. 
Table 1. Frequency and Percentage Distributions Related to Students' Demographic Characteristics

\begin{tabular}{llll}
\hline Variance & Groups & $\mathrm{n}$ & \% \\
\hline \multirow{3}{*}{ Gender } & Female & 112 & 56.0 \\
& Male & 88 & 44.0 \\
& Total & 200 & 100 \\
Doing Sports & Athlete & 76 & 38.0 \\
& Sedentary & 124 & 62.0 \\
& Total & 200 & 100 \\
& 14 & 34 & 17.0 \\
Age & 15 & 92 & 46.0 \\
& 16 & 57 & 28.5 \\
Sports Branch & 17 & 16 & 8.0 \\
& Total & 1 & .5 \\
Academic Success Level & Individual & 200 & 100 \\
& Team & 18 & 23.7 \\
& Total & 58 & 76.3 \\
\end{tabular}

\subsubsection{Qualitative Study Group}

In order to specify the qualitative study group, the data obtained from the psychological resilience scale were ranked from large to small on the basis of the total score, and the participants with the highest and the lowest psychological resilience score were determined from both groups. Accordingly, a total of 16 semi-structured interviews were realized with 200 participants, 8 of which were the highest and lowest in the psychological resilience scale among 200 students who participated in the study.

\subsection{Collection of Data}

The gathering of research data took place in two stages. The first stage is the collection of quantitative data, the second stage is the collection of qualitative data. Detailed information about both stages is presented below.

\subsubsection{Psychological Resilience Scale}

"Psychological Resilience Scale" developed by Işık (2016) was used to collect quantitative data. The psychological resilience scale consists of three sub-dimensions: Commitment, control and challenge. Psychological resilience scale is a 5-point Likert scale ranging from "certainly disagree" and "certainly agree". The Cronbach-Alpha Coefficient of the scale is the internal consistency coefficient for the commitment sub-dimension .62, the internal consistency coefficient for the control sub-dimension .69 , the internal consistency coefficient for the challenge sub-dimension. The internal consistency coefficient for the total score of 74 was .76. As a result of the scale's test-retest method, the reliability coefficient was found as .81 . The commitment dimension of psychological resilience scale, which includes individuals expressing their own perceptions, consists of articles $1,2,3,5,6,18$ and 21 . The control dimension includes articles 4, 10,11,12,15, 19, and 20. The challenge dimension consists of 7, 8, 9, 13, 14, 16 and 17th article. The 2nd and 15th articles of the scale are scored in the opposite direction. The increase in the scores obtained from the sub-dimensions of the psychological resilience scale and the overall scale refers to the high level of psychological resilience.

\subsubsection{Collection of Quantitative and Qualitative Data}

Quantitative data were collected through the scale with the voluntary participation of high school students who continue their education in Yozgat. Qualitative data were collected by preparing a semi-structured form and using interview technique. Among the participants who answered the psychological resilience scale and left their contact information on demand, eight people who accepted the interview with a score below the average and eight who accepted the interview with an average score were identified and interviewed. In qualitative research, methods were used in the validity analysis of the data obtained from the participants, rather than statistical analysis, long time spent in the working environment, putting the data and analysis under the control of the researched people, and presenting 
the data, analyzes and comments to the experts (Ekiz, 2009). In addition, coding was carried out with an independent researcher in the creation of categories in the research; A systematic process was followed through the similarities and differences that appeared in these codings. In addition, participants' views were frequently included in the study. Interviews were made with these people. Before the interviews, the permissions of the participants were obtained and the interviews were recorded. In order to determine whether the conceptual categories reached within the scope of the reliability of the study represent the themes obtained, the data were analyzed separately by another specialist besides the researcher, and the codes and the categories represented by the codes were compared. Disagreement has been discussed by both researchers and consensus has been reached. In order to ensure the reliability of the data, Miles and Huberman calculated the formula; (1994) (Consensus / (Consensus + Disagreement) x 100). Consensus among experts was calculated as $96 \%$ for the reliability of the study results.

\subsection{Analysis of Data}

The data collected in accordance with the purpose of the research were processed in the SPSS-22 package program. One-Way ANOVA (One-Way Analysis of Variance) was used to see whether there was a significant difference between the mean score distributions of the data obtained from the measurement tools according to the variables of Gender, Doing sports status, and Branch variables. Pearson correlation test was applied in relational analysis. Qualitative data were analyzed using the content analysis technique after the interviews were translated into the text by the researcher

\subsubsection{Identify Subsections}

It is both conventional and expedient to divide the Method section into labeled subsections. These usually include a section with descriptions of the participants or subjects and a section describing the procedures used in the study. The latter section often includes description of (a) any experimental manipulations or interventions used and how they were delivered-for example, any mechanical apparatus used to deliver them; (b) sampling procedures and sample size and precision; (c) measurement approaches (including the psychometric properties of the instruments used); and (d) the research design. If the design of the study is complex or the stimuli require detailed description, additional subsections or subheadings to divide the subsections may be warranted to help readers find specific information.

Include in these subsections the information essential to comprehend and replicate the study. Insufficient detail leaves the reader with questions; too much detail burdens the reader with irrelevant information. Consider using appendices and/or a supplemental website for more detailed information.

\subsubsection{Participant (Subject) Characteristics}

Appropriate identification of research participants is critical to the science and practice of psychology, particularly for generalizing the findings, making comparisons across replications, and using the evidence in research syntheses and secondary data analyses. If humans participated in the study, report the eligibility and exclusion criteria, including any restrictions based on demographic characteristics.

\subsubsection{Sampling Procedures}

Describe the procedures for selecting participants, including (a) the sampling method, if a systematic sampling plan was used; (b) the percentage of the sample approached that participated; and (c) the number of participants who selected themselves into the sample. Describe the settings and locations in which the data were collected as well as any agreements and payments made to participants, agreements with the institutional review board, ethical standards met, and safety monitoring procedures.

\subsubsection{Sample Size, Power, and Precision}

Along with the description of subjects, give the mended size of the sample and number of individuals meant to be in each condition if separate conditions were used. State whether the achieved sample differed in known ways from the target population. Conclusions and interpretations should not go beyond what the sample would warrant.

\subsubsection{Measures and Covariates}

Include in the Method section information that provides definitions of all primary and secondary outcome measures and covariates, including measures collected but not included in this report. Describe the methods used to collect data (e.g., written questionnaires, interviews, observations) as well as methods used to enhance the quality of the measurements (e.g., the training and reliability of assessors or the use of multiple observations). Provide information on instruments used, including their psychometric and biometric properties and evidence of cultural validity. 


\subsubsection{Research Design}

Specify the research design in the Method section. Were subjects placed into conditions that were manipulated, or were they observed naturalistically? If multiple conditions were created, how were participants assigned to conditions, through random assignment or some other selection mechanism? Was the study conducted as a between-subjects or a within-subject design?

\subsubsection{Experimental Manipulations or Interventions}

If interventions or experimental manipulations were used in the study, describe their specific content. Include the details of the interventions or manipulations intended for each study condition, including control groups (if any), and describe how and when interventions (experimental manipulations) were actually administered.

The text size of formula should be similar with normal text size. The formula should be placed in the middle and serial number on the right. For example:

\section{Findings}

\subsection{Findings Related to Quantitative Data}

In the Table 2 the t-test results related to the significant difference in psychological resilience levels of students according to their gender presented.

Table 2. T-Test Results Related to Significant Differences in Psychological Resilience Levels According to Students' Gender

\begin{tabular}{|c|c|c|c|c|c|c|c|}
\hline & Gender & $\mathrm{N}$ & $\overline{\mathrm{x}}$ & Ss & $\mathrm{t}$ & $\mathrm{df}$ & $\mathrm{p}$ \\
\hline \multirow{2}{*}{ Commitment } & Female & 112 & 2.61 & .550 & \multirow{2}{*}{-2.286} & \multirow{2}{*}{198} & \multirow{2}{*}{$.023 *$} \\
\hline & Male & 88 & 2.80 & .602 & & & \\
\hline \multirow{2}{*}{ Control } & Female & 112 & 2.60 & .506 & \multirow{2}{*}{-.179} & \multirow{2}{*}{198} & \multirow{2}{*}{.858} \\
\hline & Male & 88 & 2.62 & .532 & & & \\
\hline \multirow{2}{*}{ Challenge } & Female & 112 & 3.03 & .508 & \multirow{2}{*}{.138} & \multirow{2}{*}{198} & \multirow{2}{*}{.890} \\
\hline & Male & 88 & 3.04 & .582 & & & \\
\hline
\end{tabular}

When Table 2 is examined, it is examined whether there is a significant difference between the psychological resilience levels of the students according to their gender. It is seen that there is a significant difference in the sub-dimension of self-commitment according to the gender of the students $(p<0.05)$. This significant difference arises from the fact that the mean scores $(\overline{\mathrm{x}}=2.80)$ obtained by male students from the commitment sub-dimension are higher than the mean scores $(\overline{\mathrm{x}}=2.61)$ obtained by the female students from the commitment dimension. Although there is no significant difference between control and challenge sub-dimensions and psychological resilience levels by gender, it is seen that the average score of male students is higher than female students.

Table 3 shows the t-test results regarding the meaningful difference in psychological resilience levels according to the students' sports status.

Table 3. T Test Results Regarding Significant Differences in Psychological Resilience Levels According to Students' Doing Sports Status

\begin{tabular}{|c|c|c|c|c|c|c|c|}
\hline & Sports Level & $\mathrm{N}$ & $\overline{\mathrm{x}}$ & ss & $\mathrm{t}$ & $\mathrm{df}$ & $\mathrm{p}$ \\
\hline \multirow{2}{*}{ Commitment } & Athlete & 76 & 2.8195 & .57160 & \multirow[b]{2}{*}{2.393} & \multirow[b]{2}{*}{198} & \multirow{2}{*}{$.018^{*}$} \\
\hline & Sedentary & 124 & 2.6198 & .57371 & & & \\
\hline \multirow{2}{*}{ Control } & Athlete & 76 & 2.7218 & 49646 & \multirow{2}{*}{2.473} & \multirow{2}{*}{198} & \multirow[b]{2}{*}{$.014^{*}$} \\
\hline & Sedentary & 124 & 2.5380 & .51816 & & & \\
\hline \multirow{2}{*}{ Challenge } & Athlete & 76 & 3.1203 & .50793 & \multirow{2}{*}{1.787} & \multirow{2}{*}{198} & \multirow{2}{*}{.076} \\
\hline & Sedentary & 124 & 2.9804 & .55473 & & & \\
\hline
\end{tabular}

Table 3 examines whether there is a significant difference between the psychological resilience levels of the students according to their sports status. It is seen that there is a significant difference in the sub-dimension of self-commitment according to the students doing sports $(\mathrm{p}<0.05)$. This significant difference is due to the fact that the sports students' mean scores from the sub-dimension $(\overline{\mathrm{x}}=2.81)$ higher than the sub-dimension of the sedentary 
students from the sub-dimension $(\overline{\mathrm{x}}=2.61)$. When the control sub-dimension of students according to their sports status is analyzed, it is seen that there is a significant difference compared to $(\mathrm{p}<0.05)$. This significant difference arises from the fact that the average scores $(\overline{\mathrm{x}}=2.72)$ of the sports students from the control sub-dimension are higher than the average scores $(\overline{\mathrm{x}}=2.53)$ of the sedentary students from the control sub-dimension. Although it does not show a significant difference ( $p>0.05$ ) between the students' doing sports and their challenge sub-dimensions and psychological resilience levels, the average scores of the students who do sports are higher than the students who do sports.

Table 4 shows the t-test results related to the meaningful difference in psychological resilience levels according to the branches of the students.

Table 4. T-Test Results Related to Significant Differences in Psychological Resilience Levels According to Students' Branches

\begin{tabular}{|c|c|c|c|c|c|c|c|}
\hline & Branch & $\mathrm{N}$ & $\overline{\mathrm{x}}$ & ss & $\mathrm{t}$ & $\mathrm{df}$ & $\mathrm{p}$ \\
\hline \multirow{2}{*}{ Commitment } & Individual & 18 & 2.7222 & .43956 & \multirow{2}{*}{-.825} & \multirow{2}{*}{74} & \multirow{2}{*}{.412} \\
\hline & Team & 58 & 2.8498 & .60693 & & & \\
\hline \multirow{2}{*}{ Control } & Individual & 18 & 2.8175 & .46435 & \multirow{2}{*}{.935} & \multirow{2}{*}{74} & \multirow{2}{*}{.353} \\
\hline & Team & 58 & 2.6921 & .50618 & & & \\
\hline \multirow{2}{*}{ Challenge } & Individual & 18 & 3.2778 & .40546 & \multirow{2}{*}{1.519} & \multirow{2}{*}{74} & \multirow{2}{*}{.133} \\
\hline & Team & 58 & 3.0714 & .52931 & & & \\
\hline
\end{tabular}

When Table 4 is analyzed, there is no significant difference ( $p>0.05)$ between the sub-dimensions of the students' commitment, control and challenge levels and their psychological resilience levels.

One-Way Anova results regarding the difference in psychological resilience levels according to the academic success levels perceived by the participants are presented in Table 5 .

Table 5. One-Way ANOVA Results Related to the Differences in Psychological Resilience Levels According to Academic Achievement Levels of Participants

\begin{tabular}{llllllll}
\hline & Academic Success & $\mathrm{N}$ & $\overline{\mathrm{x}}$ & $\mathrm{ss}$ & $\mathrm{df}$ & $\mathrm{F}$ & $p$ \\
\hline \multirow{4}{*}{ Commitment } & Low & 33 & 2.606 & .5416 & & & \\
& Average & 132 & 2.742 & .5820 & 199 & .725 & .488 \\
& High & 35 & 2.706 & .6236 & & & \\
& Total & 200 & 2.713 & .5823 & & & \\
\multirow{5}{*}{ Control } & Low & 33 & 2.601 & .5589 & & & \\
& Average & 132 & 2.623 & .5535 & 199 & .144 & .866 \\
& High & 35 & 2.671 & .6189 & & & \\
& Total & 200 & 2.628 & .5638 & & & \\
\multirow{5}{*}{ Challenge } & Low & 33 & 3.077 & .5013 & & & .402 \\
& Average & 132 & 2.997 & 5316 & 199 & .917 & \\
& High & 35 & 3.126 & .6068 & & & \\
Total & Total & 200 & 3.033 & .5404 & & & \\
& Low & 33 & 2.782 & .4170 & & & \\
& Average & 132 & 2.782 & .4627 & 199 & .200 & .818 \\
& High & 35 & 2.836 & .5063 & & & \\
\hline
\end{tabular}


When Table 5 is analyzed, it is determined that there is no significant difference between the participants according to the perceived academic achievement level variable in the level of commitment, control, challenge and general psychological resilience $(\mathrm{p}>0.05)$. In the sub-dimensions where there is a difference, it is seen that the students who perceive the academic achievement level as high in all dimensions except the commitment dimension are higher than the students who perceive low and medium levels, but the difference is not significant.

Correlation test results showing the relationship between athletes' ages and their psychological resilience levels are given in Table 6.

Table 6. Correlation Test Results Indicating the Relationship between the Age of the Participants and the Level of Psychological Resilience

\begin{tabular}{cccccc}
\hline Variances & & Commitment & Control & Challenge & Total \\
\hline \multirow{2}{*}{ Age } & Pearson Correlation & -.077 & -.103 & .042 & -.066 \\
& $\mathrm{P}$ & .139 & .073 & .276 & .177 \\
& $\mathrm{~N}$ & 200 & 200 & 200 & 200 \\
\hline
\end{tabular}

When Table 6 is monitored, it is understood that there is no statistically significant relationship between the ages of the participants and their control, challenge sub-dimensions, and overall psychological resilience levels.

Table 7. Distribution of Participants' Psychological Resilience Score Averages

\begin{tabular}{lccc}
\hline Sub Dimensions & $\mathrm{N}$ & $\overline{\mathrm{x}}$ & Ss \\
\hline Commitment & 200 & 2.7136 & .58236 \\
Control & 200 & 2.6283 & .56382 \\
Challenge & 200 & 3.0336 & .54043 \\
Total & 200 & 2.7917 & .46169 \\
\hline
\end{tabular}

When Table 7 is examined, the psychological resilience scale of the participants is devoted. It was determined that the total scores of control, challenge and psychological resilience were average.

\subsection{Findings Related to Qualitative Data}

In this part, the findings and interpretations of the qualitative data obtained from the analyzes made with the content analysis technique after the interviews with the study group were translated into the text by the researcher.

In the Table 8, category sub-categories and codes related to the factors affecting the psychological resilience of the participants are given.

Table 8 indicates the categories, sub-categories and codes related to factors that negatively affect the psychological resilience of the participants. "What are the factors that positively affect your psychological resilience?" In line with their answers to the question, "Factors that positively affect psychological resilience" category and three sub-categories were formed. The first subcategory is the "external motivational sources" subcategory. Some of the participants' views on the "extrinsic motivation" sub-category are given below.

"I have experienced many difficult things in my life so far, but the most important power for me to survive these difficult days is the possibilities I will present to my family in the future and I am thinking about the days I will make them comfortable." (K7). Again in this issue, K4 said; 'When you go through bad times, someone who supports you or someone who is with you at every moment makes you feel better. I can say that when I was at the bottom psychologically, the word a person told me brought me back to life." He emphasized the importance of external motivation. K5 said: 'Being supported by people around me has a positive psychological effect. The current state of illness affects me positively, that the ones I love with me and support me are the ones that affect me negatively. "

The opinions of some participants regarding the second sub-category, "Internal motivation sources" sub-category are given below.

K16 mentioned that; "It makes me feel good to appreciate when doing a job, to be supported, to realize that I am good at that job, and to know that people trust me." "It makes me happy to see that there are people around me who don't support me, or congratulate me, even if it's a little thing." He emphasized the importance of the close environment in inner motivation with his discourse. K3 said; "When I have a hard 
time, I pray that this makes me very comfortable, knowing and believing that there is a creator gives me confidence". Again K8 said; "I believe that smaller successes will bring us great successes that we want to achieve gradually because everything starts with believing, since we believe in ourselves, there is not much left behind." With this discourse, he emphasized the effect of the concept of faith on intrinsic motivation.

Some of the participants' opinions regarding the third sub-category "Activities" sub-category are presented below.

K2 mentioned; 'Actually, this epidemic affected me a lot, but it offered me opportunities to take care of myself. E.g; I have the opportunity to read books. I spend time with my computer. I sleep as much as I want most. Again in this category, K12; "For example, when I play sports, I forget all my problems, because when I am on the football field where I am the most happy, I forget the world and focus only on my work. I think the correct word is that when we are happy, a person can overcome all their troubles with one thing." With his discourse, he stated the positive effect of sport on psychological resilience.

Table 8. Category Sub-categories and Codes Related to Factors Positively Affecting Participants' Psychological Resilience

\begin{tabular}{|c|c|c|}
\hline Category & Sub Category & Codes \\
\hline & & Family support \\
\hline & & Teacher support \\
\hline & Extrinsic & Friend Support \\
\hline & Motivation & Relative Support \\
\hline & & Total \\
\hline & & Self-love \\
\hline & & Being Appreciated \\
\hline & & Being Idol \\
\hline \multirow[t]{12}{*}{ Factors Affecting Psychological Resilience Positively } & Intrinsic & Being healthy \\
\hline & Motivation & Being Successful \\
\hline & & Beliefs \\
\hline & & Get into a good university \\
\hline & & Awareness \\
\hline & & Total \\
\hline & & Set aside time for oneself \\
\hline & & Listening to music \\
\hline & Activities & Do sports \\
\hline & & Sleep Regularly \\
\hline & & Watching Movie \\
\hline & & Total \\
\hline
\end{tabular}


Table 9. Category Sub-Categories and Codes Related to Factors Affecting Participants' Psychological Resilience Adversely

\begin{tabular}{|c|c|c|}
\hline Category & Sub Category & Codes \\
\hline \multirow{15}{*}{ Factors Affecting Psychological Resilience Negatively } & \multirow{7}{*}{ Anxiety } & Future anxiety \\
\hline & & Economical problems \\
\hline & & Fear of failure \\
\hline & & Traumatophobia \\
\hline & & Necrophobia \\
\hline & & Fear of Earthquake \\
\hline & & Total \\
\hline & \multirow{5}{*}{$\begin{array}{l}\text { Social Life } \\
\text { Anxiety }\end{array}$} & Family conflicts \\
\hline & & Divorce \\
\hline & & Social Pressure \\
\hline & & Lack of justice \\
\hline & & Total \\
\hline & \multirow[t]{3}{*}{ Health } & Mutilation \\
\hline & & Covid19 \\
\hline & & Total \\
\hline
\end{tabular}

When Table 9 is examined, the participants were asked "What are the factors that negatively affect your psychological resilience?" In line with their answers to the question, "Factors affecting psychological resilience negatively" category and three sub-categories have been formed. The first subcategory is the "anxiety" subcategory. Some of the participants' views regarding the "anxiety" subcategory are given below.

K4 mentioned as follows; "For example, the time when my psychological resilience was most negatively affected was the divorce of my father and mother. Prior to this, domestic violence was already adversely affected. The economic problems after the divorce continued this negativity." Again on the same subject, K2 said this; 'The person I see differently in the family is my mother, and when I argue with her, I feel frustrated and lose myself. I regret the sentences I said in discussions in a friend environment, and I feel conscientiously disturbed. When I experience something negative in the way of my business life, which I believe and strive for, I feel myself in space for a moment and think that I will lose everything. "He stated that a negative effect in the family negatively affects psychological resilience. K9 said; "I am very afraid that something will happen to me that I will be injured or I cannot get this idea out of my mind that I will get sick." "K14 said again; After healing in a position where I was previously injured in bilateral struggle, I am afraid to go back to that position psychologically again. " K1 said; "Being able to reach the goals I want in my career life after finishing my school affects me negatively. " In this category, K5 said; "I don't want to see bad things in the news. Domestic violence social violence upset me. In addition, I am afraid to say how our country was on an earthquake zone and that a recent earthquake occurred. Taking part in events such as terrorism, the factors such as the virus outbreak, which has a global pandemic, negatively affect my psychological resilience. " In this way, he emphasized negative news.

The second sub-category is the 'social life' sub-category and some participants' views on this sub-category are given below.

K4 said: "Some of them adapt more easily to difficult conditions. It overcomes the traumatic events faster. But it is a fact that there are events in our lives that negatively affect our psychological resilience. For example, the time when my psychological resilience was most negatively affected was the divorce of my father and mother. "This incident comes to my mind when I was 12 years old when my parents were separated and I didn't want to go to school because I felt so bad and I did not want to go to school at that time." K3 said: "An event in the family environment will never be forgotten no matter how long it takes. Next time, my family and friend problems that I have experienced in every period of my life will always remain a crack." Again, K11 said this on the subject; "I cannot get out of the impact of small discussions with my family or my friends." K16; "My psychological resilience is negatively affected when I feel pressure from my environment or when I cannot do anything with the family that I value the environment." . K13 has mentioned the following; " At an early age I have encountered many obstacles I started sport in my life of which the most difficult I have shown favorite in 2010 in Turkey championship has been greeted not taken the competition by association with various excuses. Therefore, a long time I 
could not overcome this trauma. "He emphasized the importance of the concept of justice in social life with his discourse.

As the third sub-category, the "Health" sub-category was created. The opinions of the participants for this sub-category are given below.

K2 said: " The disability I had while I was preparing in the physical education lesson negatively affected me in every way. " Again in this category, K5 mentioned this; "Factors such as the virus outbreak with a global pandemic negatively affect my psychological resilience." With this discourse, he emphasized the effects of epidemic diseases on psychological resilience.

\section{Discussion and Result}

It was concluded that there was no statistically significant difference between the participants in the level of control and challenge sub-dimensions according to gender, and the level of general psychological resilience. On the other hand, a significant difference emerged in favor of male participants. When the literature is analyzed, it is understood that there are no differences in the level of psychological resilience according to gender in some studies and some studies have been found. Çelik (2018) stated in his study on athletes and sedentary individuals that there was no statistically significant difference in the level of commitment and challenge sub-dimensions according to gender variable and overall psychological resilience level. Turgut and Eraslan Çapan (2017) determined that gender is not related to psychological well-being in their study on adolescents. In addition, Eraslan (2015) examined psychological well-being levels in terms of gender variables in his study on Physical Education and Sports School students and determined a significant difference in favor of female students. Tonga (2014) stated that there is a significant difference in favor of men in his study. In contrast to the literature, Desti's (2017) study on university students revealed that psychological resilience has a higher score in favor of male participants. In the current study; The reason why male students get higher scores in terms of commitment than female students may be due to the fact that male participants do not feel helpless and control the results of the events when they encounter difficulties.

According to the doing sports variance, there is a statistically significant difference found in the levels of psychological resilience in favor of students doing sports in self-commitment and control sub-dimensions. Although the students do not show a significant difference between their sports and their challenging sub-dimensions and psychological resilience levels, it is concluded that the average scores of the students doing sports are higher than the average scores of the students doing team sports. When the studies conducted in the literature are examined, the results of the studies generally overlap with the current research results. In the study that Mehrparvar and Soltani (2013) compared the psychological resilience of male students that do sports and ones that do not do sports, it was concluded that there was no difference between the psychological resilience levels of the sports students. Cevada et al. (2012) concluded that psychological resilience levels of athletes were significantly higher in their study on individuals who did not do sports with athletes. According to Cihan and Ilgar (2018), even when sportive activity is done in digital environment; It has been determined that it has positive effects such as psychological well-being, happiness, optimism and self-respect. In another study, Johnson (2015) concluded that the general psychological resilience scores of the individuals who do sports are significantly higher than those who do not do sports in their study on the level of psychological resilience in young people. Considering the current research results, it may be because the students who do sports have higher average scores than sedentary individuals, they have no choice but to learn that athletes encounter different stress factors in the competition and struggle with these stress factors in order to be successful in their job.

It was concluded that there was no statistically significant difference in Commitment, control, challenge sub-dimension and general psychological resilience levels according to the sports branches of the participants. Considering the literature; Bingöl (2015) in his study; examined the psychological resilience levels of athletes in different branches; concluded that the level of psychological resilience of athletes engaged in individual and team sports did not differ. When the current research results are taken into consideration, it is determined that there is no relationship between the students with high academic success, while the psychological resilience score averages are expected to increase. This difference may be due to the difference in the sample group.

When the qualitative results of the research are analyzed, they emphasize that while the participants are away from the answers and negativities (loneliness, anxiety and burnout) that cause mental imbalance in their lives, the sport directly and indirectly increases the capacity to cope with and resist against many negativities. When the literature is examined; the contribution of sports in eliminating the negatives is emphasized by many researchers. Inal (2014) stated that while developing the psychological benefits of sports, it improved the personality positively and increased 
the struggle and stamina. Steptoe and Butler (1996) in his research on "participation in sports and emotional well-being in adolescents", concluded that there is a positive relationship between emotional well-being and participation in sports. In addition, Dehkordi (2011) compared the mental health of women who do not do sports with women athletes and states that athletes are superior to those who do not do sports. A strong individual, both mentally and socially, stressed that he could easily cope with the diseases of the age, such as loneliness and stress. Demers (2013) completed a research on the relationship between exercise and mental health in university students and stated that at the end of the study, participation in moderate exercises can be used as an additional tool to alleviate the symptoms of depression and anxiety of university students.

It is possible that athletes who learn to fight against the various negativities they face in competition conditions and sports lives will be more resilient than individuals who do not do sports psychologically. He emphasized that it is one of the indispensable ways to reach a targeted goal in combating many health problems in children, youth and adults without age restriction in physical activity. (Edwards and Thouros, 2006). In addition, the Ministry of Health of the Republic of Turkey (2012) and Yildirım and Bayrak (2019) stated that sports increase tolerance towards life, interpersonal social communication skills and individuals' ability to deal with burnout anxiety, etc. psychological disorders by enjoying life. Hall (2011) stated that sports provides a balance of responsibility and enjoyment for young men, not only individually, psychological resilience, but also contributes to the well-being and psychological resilience of the communities in which they live. As can be seen from the above studies, sports play an important role in increasing psychological resilience and protection from stressors. It is estimated that the problems of stress and unhappiness, which are the illnesses of our era, are eliminated and the prescription of the individual's psychological well-being is written as a result of positive results.

In line with the results obtained from the research, the following suggestions are included.

- In cooperation with universities and local administrations, especially sports, exercise and recreational activities can be planned, and activities that keep students' psychological resilience levels high and away from the exam atmosphere and future anxiety can be organized.

- With the coordination work carried out by the Ministry of National Education and sports science people, projects that will raise awareness especially in terms of students and parents who indicate the importance of movement education can be proposed.

- The research has been done only on high school students. The study can be repeated with a larger sample group. Thus, longitudinal studies covering the thoughts of the parents can be revealed.

\section{References}

Adler, A. (1999). Psychological activity in normal life and work life (Translated by: Belkıs Çorakçı). Istanbul: Say Publishing House.

Bicer, T. (2002). Winning begins in the brain. Istanbul: Beyaz Publisher.

Bingöl, E. (2015). Examination of exercise addiction and psychological resilience levels of athletes in different branches (Master Thesis). Muğla Sitkı Koçman University Institute of Health Sciences. Muğla.

Callahan, D. (1973). The WHO definition of health. The Hastings Center Studies, 1(3), 77-87. https://doi.org/10.2307/3527467

Cevada, T., Cerqueira, L. S., Moraes, H. S., Santos, T. M., Pompeu, F. A. M. S., \& Deslandes, A. C. (2012). Relationship between sport, resilience, quality of life and anxiety. Archives of Clinical Psychiatry (São Paulo), 39(3), 85-89. https://doi.org/10.1590/S0101-60832012000300003

Cihan, B. B., \& Arac Ilgar, E. (2018). Determination of Curiosity Levels of High School Students Doing Sports and Non-Sports (Sedentary). Ahi Evran University Kirsehir Faculty of Education Journal, 19(2), 1649-1660. https://doi.org/10.29299/kefad.2018.19.02.016

Cihan, B. B., \& Arac Ilgar, E. (2019). A Phenomenological Analysis of the Effects of Digital Sports Games on Athletes. Gaziantep University Journal of Sports Sciences, 4(1), 171-189.

Coleman, J., \& Hagell, A. (2007). The nature of risk and resilience in adolescence. Senior Research Fellow, Universty of Oxford.

Creswell, J. W., \& Plano Clark, V. L. (2014). Design and maintenance of mixed method research (Y. Dede and S.B. Demir, Trans. Eds.). Ankara: Anı Publications. 
Çelik, O. B (2015). Psychological resilience profiles of elite athletes and sedentary individuals (Doctoral Thesis). Gazi University, Institute of Educational Sciences. Ankara.

Dehkordi, A. G. (2011). The comparison between athlete females and non-athlete females regarding to general health, mental health, and quality of life. Procedia Social and Behavioral Sciences, 15, 1737-1741. https://doi.org/10.1016/j.sbspro.2011.03.361

Demers, N. R. (2013). The relationship between exercise and mental health in college students (Master's Thesis). North Dakota State University. Fargo, North Dakota.

Desai, R. B. (2017). Psychological hardiness among college students. The International Journal of Indian Psychology, 4(3), 80-84.

Edwards, P., \& Tsouros, A. (2006). Supporting physical activity and active living in the urban environment. Scientific Evidence, World Health Organization.

Ekiz, D. (2009). Scientific research methods: Approach, methods and techniques. Ankara: An1 Publications.

Eraslan, M. (2015). Examining the psychological well-being levels of physical education and sports school students according to their age, gender and sports. International Journal of Sports Sciences, 1(1), 14-21.

Faller, G. (2001). Positive psychology: A paradigm shift. Journal of Pastoral Counseling, 36, 7-20.

Gable, S. L., \& Haidth, J. (2005). What (and why) is positive psychology? Review of General Psychology, 9(2), 103-110. https://doi.org/10.1037/1089-2680.9.2.103

Garmezy N. (1993) Children in Poverty: Resilience despite Risk. Psychiatry, 56, 127-136. https://doi.org/10.1080/00332747.1993.11024627

Gizir, C. A. (2016). A review study on psychological resilience, risk factors and protective factors. Turkish Journal of Psychological Counseling and Guidance, 28(3), 113-128.

Gizir, C. A. (2004). Academic Soundness: Protective Factors Contributing to Academic Achievement of Eighth Grade Students in Poverty (Ph.D. Thesis). METU Department of Educational Sciences, Ankara.

Hall, N. (2011). "Give it everything you got": Resilience for young males through sport. International Journal of Men's Health, 10(1), 65-81. https://doi.org/10.3149/jmh.1001.65

Hayes, N. (2011). Understanding psychology (Translated: Filiz Şar, Asiye Hekimoğlu). Istanbul: Optimist.

Hefferson, K., \& Boniwell, I. (2014). Positive Psychology: Theory, Research and Practices (Translated Ed: Tayfun Doğan). Ankara: Nobel Publishing.

Holt, P., Fine, M. J., \& Tellefson, N. (1987). Mediating stress: Survival of the hardy. Psychology in the Schools, 24, 51-58. https://doi.org/10.1002/1520-6807(198701)24:1<51::AID-PITS2310240110>3.0.CO;2-8

Işık, Ş. (2016). Development of Psychological Resilience Scale: Validity and Reliability Study. The Journal of Happiness \& Well-Being, 4(2), 165-182.

Johnson, J. (2015). Participation in sports and the development of resilience in adolescents (Master's Thesis). Brigham Young University, Provo, Utah.

Johnson, R. B., Onwuegbuzie, A. J., \& Turner, L. A. (2007). Toward a definition of mixed methods research. Journal of Mixed Methods Research, 1(2), 112-133. https://doi.org/10.1177/1558689806298224

Judkins, S. K., \& Furlow, L. (2003). Creating a hardy work environment: Can organizational policies help? Texas Journal of Rural Health, 21(4), 11-17.

Judkins, S. K., \& Rind, R. (2005). Hardiness, stress, and job satisfaction among home care nurses. Home Health Care Management and Practice, 17(2), 113-118. https://doi.org/10.1177/1084822304270020

Klag, S., \& Bradley, G. (2004). The role of hardiness in stress and illness: An exploration of the effect of negative affectivity and gender. British Journal of Health Psychology, 9, 137-161. https://doi.org/10.1348/135910704773891014

Maddi, S. R., Harvey, R. H., Khoshaba, D. M., Lu, J. L., Persico, M., \& Brow, M. (2006). The personality construct of hardiness, III: Relationships with repression, innovativeness, authoritarianism, and performance. Journal of Personality, 74(2), 575-598. https://doi.org/10.1111/j.1467-6494.2006.00385.x

Maslow, A. (2001). Psychology of Being Human. Istanbul: Kuraldısı Publishing. 
Masten A. S., Best, K. M., \& Garmezy, N. (1990). Resilience and Development: Contributions from the Study of Children Who Overcome Adversity. Dev Psychopathol, 2, 425-444. https://doi.org/10.1017/S0954579400005812

Masten, A. S., \& O'Connor, M. J. (1989). Vulnerability, stress, and resilience in the early development of a high risk child. Journal of the American Academy of Child and Adolescent Psychiatry, 28, 274-278. https://doi.org/10.1097/00004583-198903000-00021

Mehrparvar, A., \& Soltani, M. K. (2013). A comparison of psychological hardiness in male athlete and non-athlete students. European Journal of Experimental Biology, 3(1), 627-630.

Miles, M. B., \& Huberman, A. M. (1994). Qualitative data analysis: An expanded sourcebook. Thousand Oaks: Sage.

Rutter, M. (2006). Implications of resilience concepts for scientific understanding. Annals of the New York Academy of Sciences, (Resilience in Children), 1094, 1-12. https://doi.org/10.1196/annals.1376.002

Steptoe, A., \& Butler, N. (1996). Sports participation and emotional wellbeing in adolescents. Lancet, 347, 1789-1792. https://doi.org/10.1016/S0140-6736(96)91616-5

Tonga, Z. (2014). Examination of psychological resilience of university students according to decision strategies and state trait anxiety levels (Master Thesis). Gazi University Institute of Educational Sciences, Ankara.

Tugade, M. M., Fredrickson, B., \& Barret, L. F. (2004). Psychological resilience and positive emotional granularity: examining the benefits of positive emotions on coping and health. Journal of Personality, 72(6), 1161-1190. https://doi.org/10.1111/j.1467-6494.2004.00294.x

Turgut, Ö., \& Eraslan Çapan, B. (2017). Predictors of Adolescent Psychological Resilience Level: Perceived Social Support and School Commitment. Mehmet Akif Ersoy University Journal of Education Faculty, 1(44), 162-183. https://doi.org/10.21764/maeuefd.309934

Tusaie, K., \& Dyer, J. (2004). Resilience: A Historical Review of the Construct. Holist NursPract, 18, 3-8. https://doi.org/10.1097/00004650-200401000-00002

Tümlü, G. Ü., \& Recepoğlu, E. (2013). The relationship between psychological resilience and life satisfaction of university academic staff. Journal of Higher Education and Science, 3(3), 205-213.

Yağbasanlar, O. (2018). Investigation of the Relationship between the Psychological Resilience and Religious Orientation and Self-Compassion of University Students (Master Thesis). Gazi University, Institute of Educational Sciences, Ankara.

Y1ldırım, M., \& Bayrak, C. (2017). Determining the level of participation of university students in physical activities according to their demographic characteristics (Eskişehir Osmangazi University example). The Journal of Academic Social Science, 5(54), 310-330.

Yıldırım, M., \& Bayrak, C. (2019). Participation of university students in physical activities based on sports and the effect of their quality of life on academic achievement and socialization (Eskişehir Osmangazi University example). Hacettepe University Faculty of Education Journal, 34(1), 123-144. https://dx.doi.org/10.16986/HUJE.2017032928

Zorba, E., Cerit, A., Gümüşdağ, H., \& Evli, M. (2013). Investigation of reasons for preference of recreation departments and expectations of department students. International Refereed Academic Sports Health And Medical Sciences Journal, 8(3). 